\title{
Job Satisfaction and Associated Factors among Health Care Staff in Township Health Centers-- A Cross-Sectional Survey in Rural Central China
}

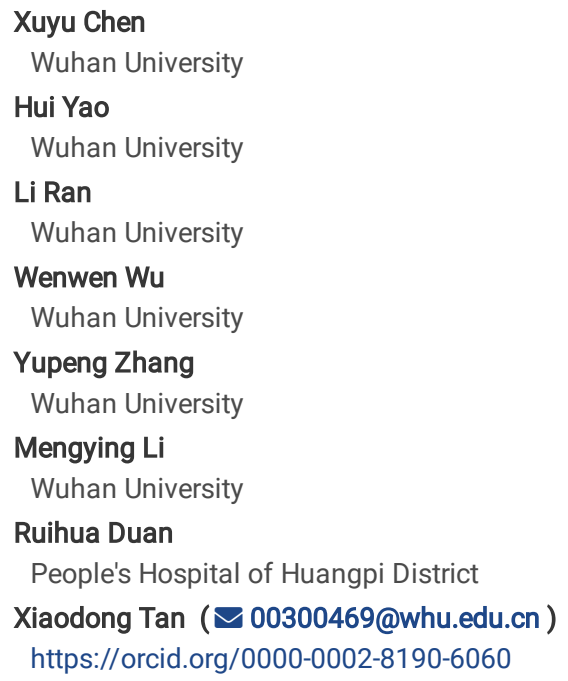




\section{Abstract}

Background:Township health centers play a cornerstone role in the work of primary health care in China while it's development is largely limited by the brain dr: care staff in township health centers in Huangpi District. Methods: This research was conducted in Huangpi, China. Convenience sampling methods and selfadministereded questionnaires were used. 1370 of valid samples were collected with $97.72 \%$ effective rate. Descriptive statistics are used to describe socioden square statistical was used to test the binary association between job satisfaction and another categorical variable. All the sociodemographic information was Conclusions: Government and management should consider the impact of current policies on job satisfaction to reduce staff's personal job dissatisfaction, Re

\section{Background}

Primary health care is widely perceived to be the backbone of a national health care system(1), and township health centers serve as a central role in primary health care to ensure the implementation of many functions of health service at the grass-roots level in rural areas(2). However, for a long time, the shortage of personnel is prominent due to difficulties in recruitment and serious wastage in rural health institutions, especially township health centers(3). A study conducted by Yang et al (4) indicated that China's rural health resources are extremely deficient, compared with other types of human resources for health. The shortage of professionals in health care centers will eventually affect the health of the rural population and exacerbate health inequality. Some studies $(5,6)$ have shown that improving job satisfaction is crucial for reducing turnover intention among personnel in township health centers.

Job satisfaction originated from Hawthorne's experiment to study the work efficiency of workers. Hoppock (7)first put forward the concept of job satisfaction, with the definition of a subjective evaluation of their work status from a personal point of view. Locke (8) believes that job satisfaction represents the emotional state generated by the achievement of one's job value in the work situation. After years of development, Scholars have put forward the definition of job satisfaction from different angles and enriched its connotation and dimension. In this study, we are prefer to use the definition: The psychological state in which an individual has a benign feeling about the work itself and its related parties in the process of working within the organization, including working environment, working status, working style, work stress, challenge, interpersonal relationship at work, etc(9).

In 1935, Hoppock used the attitude scale for the first time to evaluate job satisfaction, but he focused more on the material level of work, lacking the influence of internal factors on employees. Later scholars developed a number of relatively mature evaluation scales on this basis, most of which include promotion opportunity, salary, colleague relationship and work itself (10-12). Although there are a variety of concepts and measurement methods of job satisfaction, almost all scholars agree that the concept of job satisfaction can reflect job-related psychological behavior.

The health personnel in township health centers are the practical practitioners of rural health services and the promoters of health policies, relating to the sustainable development of rural health services closely. A survey conducted by Shahnazi H (13) indicated that the quality of health services decreases with the decline of satisfaction. For health care staff, low job satisfaction can cause damage to their physical and mental health, and reduce well-being(14-16). For medical institutions, there will be an increase in doctor-patient conflicts and a decline in performance with the increase of low satisfaction. Thus, assessment of job satisfaction among health personnel is essential.

Huangpi District first put forward the concept of health management association, and became a demonstration area of national health management association in 2013. People have obtained more convenient, effective and inexpensive medical services, with the deepening of the system. However, the research on the satisfaction of health care workers after the innovation are few in Huangpi. Previous studies have focused more on patient satisfaction and less on doctors' satisfaction. The purpose of this study was to investigate job satisfaction and its related influencing factors in the context of health management consortium among health care staff.

\section{Methods}

\section{Settings and Participants}

A cross-sectional survey was used. The research was based on the programme which named "Third party evaluation of comprehensive effect of medical and health institutions in Huangpi district". The programme was conducted from March 2018 to June 2019. Convenience sampling methods was used. We utilized data of medical staffs from township health centers in the rural areas. Eligible participants met the following inclusion criteria: (1) Time of service was more than one year. (2) There had been no mental damage recently. (3) Medical personnel must have qualifications. (4) Participants were voluntary. The exclusion criteria were as follows: (1) Employees who had less than one year of service time. (2) There had been mental damage recently. (3) Staff without qualifications were not included. 1402 questionnaires were distributed, and questionnaires with missing values were excluded. Finally, a total of 1370 of valid samples were collected with $97.72 \%$ effective rate.

\section{Measures}

The original questionnaire was developed by Zhang et al (17). The questionnaire was adapted from the Minnesota Satisfaction Questionnaire (MSQ)(18), the Job Satisfaction Survey (JSS)(19) and the Job Descriptive Index(20), and it has been proved that the reliability and validity were acceptable. The questionnaire we used involved the two parts: sociodemographic information and job satisfaction.

The sociodemographic measures include gender, age, educational background, marital status, professional status, occupation, monthly income (RMB), hire form, hours worked per week, years of service, night shift frequency (times a month). The job satisfaction portion in the questionnaire includes 18 items which 
evaluate satisfaction with work environment (facility, cooperation, interpersonal relationship, and leadership), remunerations, management and the work itself. A five-point Likert scale was adopted, all questions were positive scoring ( $5=$ strongly agree, $4=$ agree, $3=$ neutral, $2=$ disagree, $1=$ strongly disagree $)$.

The value of Kaiser-Meyer-Olkin (KMO) is 0.96 , and Bartlett's test was significant at $\chi^{2}(0.05,153)=34832.83(p<0.01)$. Cronbach's alpha was used to evaluate the reliability of the questionnaire, exploratory factor analysis (EFA) was performed to test the construct validity. The value of Cronbach's alpha reflects the internal consistency of the questionnaire. It is generally considered that a value above 0.90 is excellent, above 0.80 is good and above 0.70 is acceptable. As shown in Table 1, the Cronbach's alpha value of each dimensions ranged from 0.89 to 0.98 , which indicated the reliability of the questionnaire is good. The construct validity was acceptable if the factor loading of each item was greater than $0.40(21)$, and the factor loading of each item met the criteria. The four factors were named as "working environment", "management rules", "remunerations" and "the work itself", respectively.

Table 1

Factor loading of items using the exploratory factor analysis and Cronbach's a of the questionnaire

\begin{tabular}{|c|c|c|c|c|}
\hline \multirow[t]{2}{*}{ Items } & \multicolumn{4}{|c|}{ Factor } \\
\hline & 1 & 2 & 3 & 4 \\
\hline 1.The comfort level of the working environment (office environment, greening, lighting, etc). & 0.81 & & & \\
\hline $\begin{array}{l}\text { 2.The organization can provide sufficient technical equipment (professional information inquiry resources, } \\
\text { instruments, etc.) for work use. }\end{array}$ & 0.81 & & & \\
\hline 3 Interpersonal relationship within the organization (peer relationship and subordinate relationship). & 0.88 & & & \\
\hline 4.Happy cooperation between different departments within the organization. & 0.85 & & & \\
\hline 5.The work style of the organization is very good. & 0.79 & & & \\
\hline 6. The leadership of the workplace is very good. & 0.80 & & & \\
\hline 7.Current income level satisfied you. & & 0.78 & & \\
\hline 8. The welfare of the work organization satisfied you. & & 0.79 & & \\
\hline 9. Work development prospects satisfied you. & & 0.77 & & \\
\hline 10.Satisfaction with the training opportunities (number, form and content) offered . & & 0.70 & & \\
\hline 11.The income distribution system of the organization is reasonable. & & & 0.78 & \\
\hline 12.The performance appraisal mechanism of the organization is set up reasonably. & & & 0.77 & \\
\hline 13.The performance of the organization's performance reward system is good. & & & 0.77 & \\
\hline 14. The management system and business process of the organization are good. & & & 0.69 & \\
\hline 15.I am very interested in my current job. & & & & 0.75 \\
\hline 16.My character and ability suit current position. & & & & 0.68 \\
\hline 17.My work is very challenging. & & & & 0.65 \\
\hline 18.I feel that my daily work tasks are heavy. & & & & 0.78 \\
\hline Eigenvalue & 10.60 & 3.03 & 1.30 & 1.02 \\
\hline$\%$ variance & 59.97 & 72.01 & 82.90 & 85.69 \\
\hline Cronbach's alpha & 0.96 & 0.96 & 0.98 & 0.89 \\
\hline
\end{tabular}

\section{Statistical analysis}

Job satisfaction of healthcare staff was transformed into a binary categorical variable based on the mean score of all items. Job satisfaction was regarded as the dependent variable $(Y)$, and it was divided into two groups: 1 "satisfied" (a mean score higher than or equal to 3.50(21)) and 0 "unsatisfied" (a mean score lower than $3.50(21)$ ). The sociodemographic information was regarded as independent variable (X). Gender was divided into two groups, 1 "male" and 0 "female". Age was divided into four groups: less than 30 years, 31-40 years, $41-50$ years and more than 50 years. Educational background was divided into four groups: university and above, junior college, high school or technical school, junior high school and below. Marital status also was divided into four groups: married (living with spouse), married (not living with spouse), unmarried, divorced or widowed. Professional status was divided into four groups: senior/deputy, intermediate, primary, lower than primary (22). Occupation was divided into four groups: clinicians, nurse, public health staff, other occupation. Monthly income was divided into five groups: less than 2000 RMB, 2001-3000 RMB, 3001-4000 RMB, 4001-5000 RMB, more than 5000 RMB. Hire form was divided into three groups: personnel agent staff, permanent staff, temporary staff. Hours worked per week was divided into four groups: less than 31 hours, 31-40 hours, 41-50 hours, more than 50 hours. Years of service was divided into five groups: 1-5 years, 6-10 years, 11-15 years, 15-20 years, more than 20 years. Night shift frequency was divided into three groups: 0 times, 1-3 times and more than 3 times. The last group of each independent variable was used as a reference group to set the dummy variable. 
Using EpiData (version 3.0) to establish a database for data entry and conversion. Double machine imputing method was used to enter the collected data into the computer. Descriptive statistics are used to describe sociodemographic information. The Pearson Chi-square statistical was used to test the binary association between job satisfaction and another categorical variable. All the sociodemographic information was applied to the binary logistic regression model using the stepwise selection method. Odds Ratio (OR) and 95\% Confidence Interval (CI) of the variables were reported. Using SPSS version 20.0 (IBM Corp, Armonk, NY, USA) to analyze data, all tests were conducted at the 0.05 level of statistical significance.

\section{Results}

\section{Descriptive of Sociodemographic Characteristics}

The sociodemographic characteristics of the respondents are tabulated in Table 2 with the number ( $\mathrm{n}$ ) and the corresponding percentages. In this sample, $31.09 \%$ of the participants were male and $68.91 \%$ were female. The average age of the respondents was $36.98 \pm 9.84$ years, the largest proportion of participants (35.77\%) was in the less than 31 years old group, and the least proportion of participants (7.74\%) was in the more than 50 years old group. The educational background of $46.42 \%$ of the staffs surveyed was junior college. $77.29 \%$ of the respondents was married, and $72.26 \%$ of them lived with their spouse. Most of the participants had primary professional status (52.85\%), followed by lower than primary professional status (28.83\%). The majority of the respondents were clinicians (42.77\%), followed by nurses (41.02\%). $37.88 \%$ of the respondents had a monthly income of $3001-4000$ RMB. The majority of the respondents (55.40\%) were permanent staff. $71.02 \%$ of the respondents worked for $31-40$ hours per week, and only $1.31 \%$ worked for less than 31 hours per week. Participants' average years of service were $14.65 \pm 10.87$ years. Additionally, most of the respondents (63.36\%) had no night shift per month, followed by night shift of $1-3$ times per month $(32.85 \%)$. 
Table 2

Sociodemographic characteristics of respondents $(n=1370)$

\begin{tabular}{|c|c|c|c|}
\hline Variables & Group & $\mathbf{n}$ & $\%$ \\
\hline \multirow[t]{2}{*}{ Gender } & Male & 426 & 31.09 \\
\hline & Female & 944 & 68.91 \\
\hline \multirow[t]{4}{*}{ Age(years) } & $<31$ & 490 & 35.77 \\
\hline & $31-40$ & 332 & 24.23 \\
\hline & $41-50$ & 442 & 32.26 \\
\hline & $>50$ & 106 & 7.74 \\
\hline \multirow[t]{4}{*}{ Educational background } & University and above & 423 & 30.88 \\
\hline & Junior college & 636 & 46.42 \\
\hline & High school/Technical school & 286 & 20.88 \\
\hline & Junior high school and below & 25 & 1.82 \\
\hline \multirow[t]{4}{*}{ Marital status } & Married (living with spouse) & 990 & 72.26 \\
\hline & Married (not living with spouse) & 69 & 5.03 \\
\hline & Unmarried & 270 & 19.71 \\
\hline & Divorced/widowed & 41 & 2.99 \\
\hline \multirow[t]{4}{*}{ Professional status } & Senior/deputy & 44 & 3.21 \\
\hline & Intermediate & 207 & 15.11 \\
\hline & Primary & 724 & 52.85 \\
\hline & Lower than primary & 395 & 28.83 \\
\hline \multirow[t]{4}{*}{ Occupation } & Clinicians & 586 & 42.77 \\
\hline & Nurse & 562 & 41.02 \\
\hline & Public health staff & 66 & 4.82 \\
\hline & Other occupation & 156 & 11.39 \\
\hline \multirow[t]{5}{*}{ Monthly income (RMB) } & $<2000$ & 109 & 7.96 \\
\hline & $2001-3000$ & 413 & 30.15 \\
\hline & $3001-4000$ & 519 & 37.88 \\
\hline & $4001-5000$ & 274 & 20.00 \\
\hline & $>5000$ & 55 & 4.01 \\
\hline \multirow[t]{3}{*}{ Hire form } & Personnel agent staff & 221 & 16.13 \\
\hline & permanent staff & 759 & 55.40 \\
\hline & Temporary staff & 390 & 28.47 \\
\hline \multirow[t]{4}{*}{ Hours worked per week } & $<31$ & 18 & 1.31 \\
\hline & $31-40$ & 973 & 71.02 \\
\hline & $41-50$ & 235 & 17.15 \\
\hline & $>50$ & 144 & 10.51 \\
\hline \multirow[t]{5}{*}{ Years of service } & $1-5$ & 404 & 29.49 \\
\hline & $6-10$ & 230 & 16.79 \\
\hline & $11-15$ & 134 & 9.78 \\
\hline & $15-20$ & 166 & 12.12 \\
\hline & $>20$ & 436 & 31.82 \\
\hline \multirow{2}{*}{$\begin{array}{l}\text { Night shift frequency } \\
\text { (per month) }\end{array}$} & 0 & 868 & 63.36 \\
\hline & $1-3$ & 450 & 32.85 \\
\hline
\end{tabular}

Page 5/12 


\begin{tabular}{|llll|}
\hline Variables & Group & $\mathbf{n}$ & $\%$ \\
\hline & $>3$ & 52 & 3.80 \\
\hline
\end{tabular}

\section{Univariate Analysis Using The Chi-square Test}

The results of the univariate analysis are shown in Table 3. The job satisfaction is associated with educational background $\left(\chi^{2}=7.99, p=0.046\right)$, monthly income $\left(\chi^{2}=51.43, p<0.001\right)$, hire form $\left(\chi^{2}=7.64, p=0.049\right)$, hours worked per week $\left(\chi^{2}=33.48, p<0.01\right)$, parent have had a stable job $\left(\chi^{2}=10.67, p<0.01\right)$.

Table 3

Assessment on the factors related to job satisfaction of medical staff in township health centers

\begin{tabular}{|c|c|c|c|c|c|c|c|c|c|c|c|c|}
\hline \multirow{2}{*}{$\begin{array}{l}\text { Sociodemographic } \\
\text { characteristic }\end{array}$} & \multicolumn{2}{|c|}{ Satisfied } & \multicolumn{2}{|c|}{ Unsatisfied } & \multirow[t]{2}{*}{$x^{2}$} & \multirow[t]{2}{*}{$p$} & \multirow{2}{*}{$\begin{array}{l}\text { Sociodemographic } \\
\text { characteristic }\end{array}$} & \multicolumn{2}{|c|}{ Satisfied } & \multicolumn{2}{|c|}{ Unsatisfied } & \multirow[t]{2}{*}{ ) } \\
\hline & $\mathbf{n}$ & $\%$ & $\mathrm{n}$ & $\%$ & & & & $\mathbf{n}$ & $\%$ & $\mathrm{n}$ & $\%$ & \\
\hline Gender & & & & & & & Monthly income (RN & & & & & \\
\hline Male & 311 & 22.71 & 115 & 8.39 & 1.75 & 0.19 & $<2000$ & 59 & 4.31 & 50 & 3.65 & ! \\
\hline Female & 656 & 47.88 & 288 & 21.02 & & & $2001-3000$ & 258 & 18.83 & 155 & 11.31 & \\
\hline Age & & & & & & & $3001-4000$ & 392 & 28.61 & 127 & 9.27 & \\
\hline$<31$ & 331 & 24.16 & 159 & 11.61 & 5.40 & 0.15 & $4001-5000$ & 206 & 15.04 & 68 & 4.96 & \\
\hline $31-40$ & 231 & 16.86 & 101 & 7.37 & & & $>5000$ & 52 & 3.80 & 3 & 0.22 & \\
\hline $41-50$ & 325 & 23.72 & 117 & 8.54 & & & Hire form & & & & & \\
\hline$>50$ & 80 & 5.84 & 26 & 1.90 & & & $\begin{array}{l}\text { Personnel agent } \\
\text { staff }\end{array}$ & 533 & 38.91 & 228 & 16.64 & ; \\
\hline Educational background & & & & & & & permanent staff & 169 & 12.34 & 52 & 3.80 & \\
\hline $\begin{array}{l}\text { University and } \\
\text { above }\end{array}$ & 280 & 20.44 & 143 & 10.44 & 7.99 & $0.046^{*}$ & Temporary staff & 265 & 19.34 & 125 & 9.12 & \\
\hline Junior college & 453 & 33.07 & 183 & 13.36 & & & $\begin{array}{l}\text { Hours worked per } \\
\text { week }\end{array}$ & & & & & \\
\hline $\begin{array}{l}\text { High school } \\
\text { /Technical school }\end{array}$ & 217 & 15.84 & 69 & 5.04 & & & $<31$ & 15 & 1.09 & 3 & 0.22 & $\vdots$ \\
\hline $\begin{array}{l}\text { Junior high school } \\
\text { and below }\end{array}$ & 17 & 1.24 & 8 & 0.58 & & & $31-40$ & 727 & 53.07 & 246 & 17.96 & \\
\hline Marital status & & & & & & & $41-50$ & 135 & 9.85 & 100 & 7.30 & \\
\hline $\begin{array}{l}\text { Married (living } \\
\text { with spouse) }\end{array}$ & 713 & 52.04 & 277 & 20.22 & 8.96 & 0.042 & $>51$ & 90 & 6.57 & 54 & 3.94 & \\
\hline $\begin{array}{l}\text { Married (not living } \\
\text { with spouse) }\end{array}$ & 50 & 3.65 & 19 & 1.39 & & & Years of service & & & & & \\
\hline Unmarried & 180 & 13.14 & 90 & 6.57 & & & $1-5$ & 277 & 20.22 & 127 & 9.27 & ; \\
\hline Divorced/widowed & 24 & 1.75 & 17 & 1.24 & & & $6-10$ & 155 & 11.31 & 75 & 5.47 & \\
\hline Professional status & & & & & & & $11-15$ & 98 & 7.15 & 36 & 2.63 & \\
\hline Senior/deputy & 31 & 2.26 & 13 & 0.95 & 2.24 & 0.53 & $15-20$ & 110 & 8.03 & 56 & 4.09 & \\
\hline Intermediate & 152 & 11.09 & 55 & 4.01 & & & $>20$ & 327 & 23.87 & 109 & 7.96 & \\
\hline Primary & 499 & 36.42 & 225 & 16.42 & & & Night shift frequency & r mont & & & & \\
\hline $\begin{array}{l}\text { Lower than } \\
\text { primary }\end{array}$ & 285 & 20.80 & 110 & 8.03 & & & 0 & 596 & 43.50 & 272 & 19.85 & $<$ \\
\hline Occupation & & & & & & & $1-3$ & 334 & 24.38 & 116 & 8.47 & \\
\hline Clinicians & 378 & 27.60 & 208 & 15.18 & 8.00 & 0.33 & $>3$ & 37 & 2.70 & 15 & 1.09 & \\
\hline Nurse & 420 & 30.66 & 142 & 10.36 & & & Parents have had a s & e job o & not & & & \\
\hline Public health staff & 48 & 3.50 & 18 & 1.31 & & & Yes & 383 & 27.96 & 122 & 8.91 & 1 \\
\hline Other occupation & 120 & 8.76 & 36 & 2.63 & & & No & 584 & 42.63 & 281 & 20.51 & \\
\hline
\end{tabular}




\section{Binary Logistic Regression Analysis}

Table 4 shows the relationship between individual factors and job satisfaction. Marital status, professional status, monthly income, hire form, hours worked per week, parents have had a stable job or not were significantly associated with the job satisfaction of the respondents from township health centers in rural areas of Huangpi (see Table 4). 
Binary logistic regression to explore factors assocated with job satisfaction

\begin{tabular}{|c|c|c|c|c|c|}
\hline \multirow[t]{2}{*}{ Variables } & \multirow[t]{2}{*}{ B } & \multirow[t]{2}{*}{ p } & \multirow[t]{2}{*}{ Odds Ratio } & \multicolumn{2}{|l|}{$95 \% \mathrm{Cl}$} \\
\hline & & & & lower & upper \\
\hline \multicolumn{6}{|l|}{ Gender (ref. Female) } \\
\hline Male & -0.027 & 0.857 & 0.973 & 0.726 & 1.304 \\
\hline \multicolumn{6}{|l|}{ Age (ref. $>50$ ) } \\
\hline $18-30$ & 0.180 & 0.679 & 1.198 & 0.510 & 2.815 \\
\hline $31-40$ & 0.338 & 0.374 & 1.403 & 0.665 & 2.961 \\
\hline $41-50$ & 0.220 & 0.447 & 1.246 & 0.706 & 2.198 \\
\hline \multicolumn{6}{|l|}{ Educational background (ref. Junior high school and below) } \\
\hline University and above & -0.192 & 0.697 & 0.825 & 0.313 & 2.174 \\
\hline Junior college & 0.017 & 0.972 & 1.017 & 0.396 & 2.607 \\
\hline High school/special (or technical) secondary school & 0.326 & 0.508 & 1.385 & 0.527 & 3.637 \\
\hline \multicolumn{6}{|l|}{ Marital status (ref. Divorce or widowhood) } \\
\hline Married (living with spouse) & 0.865 & $0.013^{*}$ & 2.376 & 1.205 & 4.686 \\
\hline Married (not living with spouse) & 1.001 & $0.028^{*}$ & 2.721 & 1.117 & 6.630 \\
\hline Unmarried & 0.810 & $0.046^{\star}$ & 2.247 & 1.014 & 4.979 \\
\hline \multicolumn{6}{|l|}{ Professional status (ref. Senior/deputy) } \\
\hline Lower than primary & -1.213 & $0.007 * \star$ & 0.297 & 0.123 & 0.720 \\
\hline Primary & -0.405 & 0.112 & 0.667 & 0.405 & 1.099 \\
\hline Intermediate & -0.321 & 0.056 & 0.725 & 0.522 & 1.008 \\
\hline \multicolumn{6}{|l|}{ Occupation (ref. Other occupation) } \\
\hline Clinicians & 0.963 & 0.965 & 1.231 & 0.256 & 1.289 \\
\hline Nurse & 0.654 & 0.658 & 2.324 & 0.658 & 5.369 \\
\hline Public health staff & 1.254 & 0.874 & 0.561 & 0.213 & 1.254 \\
\hline \multicolumn{6}{|l|}{ Monthly income (ref. > 5000 RMB) } \\
\hline$<2000 \mathrm{RMB}$ & -3.456 & $0.000 * *$ & 0.032 & 0.008 & 0.189 \\
\hline 2001-3000 RMB & -2.726 & $0.000 * *$ & 0.065 & 0.019 & 0.229 \\
\hline $3001-4000 \mathrm{RMB}$ & -1.847 & $0.003^{\star \star}$ & 0.158 & 0.046 & 0.542 \\
\hline $4001-5000 \mathrm{RMB}$ & -1.789 & $0.005^{\star *}$ & 0.167 & 0.048 & 0.579 \\
\hline \multicolumn{6}{|l|}{ Hire form (ref. Permanent staff) } \\
\hline Temporary staff & -0.561 & $0.009 *$ & 0.570 & 0.375 & 0.869 \\
\hline Personnel agent staff & -0.060 & 0.810 & 0.942 & 0.580 & 1.412 \\
\hline \multicolumn{6}{|l|}{ Hours worked per week (ref. >50) } \\
\hline$<31$ & 1.205 & 0.080 & 3.337 & 0.865 & 12.865 \\
\hline $31-40$ & 0.851 & $0.000 * *$ & 2.343 & 1.517 & 3.619 \\
\hline $41-50$ & -0.120 & 0.612 & 0.887 & 0.557 & 1.412 \\
\hline \multicolumn{6}{|l|}{ Years of service (ref. >21) } \\
\hline $1-5$ & -0.008 & 0.983 & 0.992 & 0.473 & 2.081 \\
\hline $6-10$ & -0.083 & 0.820 & 0.921 & 0.452 & 1.875 \\
\hline $11-15$ & -0.179 & 0.605 & 0.836 & 0.425 & 1.646 \\
\hline $16-20$ & -0.210 & 0.416 & 0.811 & 0.489 & 1.344 \\
\hline
\end{tabular}




\begin{tabular}{|c|c|c|c|c|c|}
\hline \multirow[t]{2}{*}{ Variables } & \multirow[t]{2}{*}{ B } & \multirow[t]{2}{*}{ p } & \multirow[t]{2}{*}{ Odds Ratio } & \multicolumn{2}{|l|}{$95 \% \mathrm{Cl}$} \\
\hline & & & & lower & upper \\
\hline \multicolumn{6}{|c|}{ Times of night-shift a week (ref. >3 times) } \\
\hline 0 & -0.502 & 0.151 & 0.605 & 0.305 & 1.202 \\
\hline $1-3$ & 0.301 & 0.403 & 1.352 & 0.667 & 2.738 \\
\hline \multicolumn{6}{|c|}{ Parents have had a stable job or not (ref. No) } \\
\hline Yes & 0.317 & $0.026^{*}$ & 1.373 & 1.040 & 1.814 \\
\hline Constant & 2.260 & $0.021^{*}$ & 9.583 & - & - \\
\hline
\end{tabular}

Marital status of married (living with spouse) were 2.376 times more likely to report satisfaction with their job than marital status of divorce or widowhood $(\mathrm{OR}=2.376,95 \% \mathrm{Cl}=(1.21,4.69), \mathrm{p}=0.013)$, marital status of married (not living with spouse) were 2.721 times more likely to report satisfaction than marital status of divorce or widowhood $(\mathrm{OR}=2.721,95 \% \mathrm{Cl}=(1.117,6.630), \mathrm{p}=0.028)$, marital status of unmarried were 2.247 times more likely to report satisfaction than marital status of divorce or widowhood $(\mathrm{OR}=2.247,95 \% \mathrm{Cl}=(1.014,4.979), \mathrm{p}=0.046)$. Healthcare staff who had a professional status of lower than primary were less likely to be satisfied with their job than the respondents with senior or deputy professional status $(\mathrm{OR}=0.297,95 \% \mathrm{Cl}=(0.123,0.720), \mathrm{p}<$ 0.01). Employees with lower monthly income were less likely to be satisfied with their job $(O R<2000 \mathrm{RMB}=0.032,95 \% \mathrm{Cl}=(0.008,0.189), \mathrm{p}<0.01 ; \mathrm{OR} 2001$ $3000 \mathrm{RMB}=0.065,95 \% \mathrm{Cl}=(0.019,0.229), \mathrm{p}<0.01 ; \mathrm{OR} 3001-4000 \mathrm{RMB}=0.158,95 \% \mathrm{Cl}=(0.046,0.542), \mathrm{p}<0.01 ; \mathrm{OR} 4001-5000 \mathrm{RMB}=0.167,95 \% \mathrm{Cl}=(0.048$, 0.579), $\mathrm{p}<0.01)$. Temporary staff were less likely to be satisfied with their job than permanent staff $(\mathrm{OR}=0.570,95 \% \mathrm{Cl}=(0.375,0.869), \mathrm{p}<0.01)$. Employees who worked 31 to 40 hours per week were more likely to be satisfied with their job than staff who worked more than 50 hours per week $(0 R=2.343,95 \% \mathrm{Cl}=$ $(1.517,3.619), p<0.01)$. Respondents whose parents have had a stable job were more likely to be satisfied with job than those whose parents did not have stable job $(\mathrm{OR}=1.373,95 \% \mathrm{Cl}=(1.040,1.814), \mathrm{p}<0.05)$.

\section{Disscussion}

Previous studies $(23,24)$ have shown that many factors, such as age, remuneration, educational level, working pressure, are influencing factors of job satisfaction. This study aimed to review the satisfaction of township health center staff and the associated factors in Huangpi. Township health centers serve as a central hub in primary health care in rural areas of China. Improving satisfaction is of great significance for the provision of high-quality medical services.

In the present study, there was a significant correlation between marital status and job satisfaction. Married (living with a spouse) had the highest satisfaction, followed by married (not living with a spouse), and the lowest was divorce or widowhood. The study results of Mirzraie was in accordance with our study (25). Similar study have shown that young age, being female and being married were significantly associated with a higher level of job satisfaction by Narge et al(26). However, there was no significant correlation between marital status and score of overall job satisfaction in the study of Hossein (27). Hossein divided marital status into three categories (married, single, other), while we subdivided it into four categories including married (living with spouse), married (not living with spouse), unmarried, divorced/widowed. The single status is divided into unmarried and divorced / widowed, these are two different states and the corresponding age groups varies greatly, the married state are classified as living with the spouse or not. We infer that simply dividing marital status into married and single is not conducive to finding the relationship between marital status and job satisfaction.

Healthcare staff who had a professional status of lower than primary were less likely to be satisfied with their job than the respondents with senior or deputy professional status. Similarly, a previous study has have shown that higher salary and having more leadership roles were independently associated with higher career satisfaction(28). However, a study in Guangdong Province conducted by Yong Lu(21) pointed out that empolyees with a higher professional status were less likely to be satisfied with their job than those with lower status. Participants of the above studies consisted of various types of health centers, including tertiary public hospital which undertake a large number of heavy health tasks, while our research included only medical staff of township health centers. A study have shown that medical staff in tertiary hospitals undertake the heaviest workload among those in health facilities of different levels which adversely affect the overall job satisfaction and could also develop into higher stress rating and burnout syndrome (29). This also explains why staff who work too long hours per week are less satisfied in our study. Another possible explanation is that in China, professional titles are usually associated with status and income. Staff with low professional titles enjoy less reputation and income than those with high professional titles.

This study found that the level of satisfaction was relatively higher among highly paid staff and this was consistent with a number of previous studies (3032). A study(33) among pharmacy in Maryland reported that low satisfaction with salary as a reason for intending to leave an employer. Health care staff pay more attention to remuneration because it has a direct impact on their quality of life. According to a study by Nomura $Y$ (34), salary was only the determinant for the dental hygienists who strongly disliked their work. One reason for this discrepancy may originate from the national insurance system of Japan; the Japanese insurance system covers a wide range of dental treatments, and the treatment fees are not expensive.

The result that staff who are employed on a long-term basis are more satisfied than those employed on a temporary basis was in line with other study (35). According to Simone's research (36), temporary contracts form can increase worker's vulnerability to work-related stress and therefore influence the job satisfaction. Thereby, we speculate that temporary contracts are linked to higher job insecurity. There was no significant difference in job satisfaction between personnel agents and long-term employees, combined with the actual situation of China's public medical institutions, we surmise that it is likely to be related to the fact that personnel agency system in many aspects, such as salary, performance, and benefits, has no obvious difference with long-term employees. 
In terms of the association between the parents' job stability and job satisfaction, it was found that higher satisfaction with parents having a stable job. Those whose parents have stable jobs often mean less time and financial cost in caring for elderly parents. Similar results are reported in Linda' s study (37). Another explanation is that parents with stable jobs partly means less work-family conflict and can provide more internal support from family, thereby, job satisfaction is higher than those whose parents' job is not stable.

Employees who has a moderate working hours per week reported higher levels of job satisfaction than those who work too long. Previous studies (38, 39) have also shown a negative correlation between extended work hours and job satisfaction as a whole. A possible explanation is that long working hours tend to be associated with higher workloads and higher stress levels. And compared with working too few hours, moderate working hours promote proper work enthusiasm and positive work stress.

There are a few limitations we must be open to acknowledge in this study. First, the representativeness of this sample is limited, as our sample was from the health centers in each township. Second, the questionnaire used in this study was self- administrated according to the conditions of Huangpi and has only been used in this district. Third, some of the questions such as income and work hours asked in this study were self-reported and may have generated less reliable responses. Fourth, the results only reflected the situations in Huangpi, and might not adapt to other regions due to differing implementation of policy and health system reforms across. However, the results were useful for reflecting the satisfaction situation of Huangpi especially under the reform background of health union in Huangpi District. Fifth, as the study was a cross-sectional design, the causal effects of job satisfaction could not be determined. Further study is perhaps needed for measuring the effects.

\section{Conclusion}

Healthcare staffs' job satisfaction was significantly associated with monthly income, weekly working hours, employment form, parents' work status and sociodemographic factors, including professional and marital status. As health care staff in townships are essential in providing primary services in China, the government and administrators could consider ways to enhance staff's personal job satisfaction. Given the health care staff shortage, there should be action taken to create a better balance between the number of patients and staff to reduce the workload of medical staff appropriately. Increasing personnel income especially by promoting wage equity and improving overtime allowance as well as shift work allowances is a potential strategy to ameliorate low levels of job satisfaction. Besides, scientific performance appraisal and salary distribution, professional development supporting and financial incentives are also make sense. Further research can be conducted to investigate the possible explanations.

\section{Declarations}

\section{Ethics approval and consent to participate}

As the project is in cooperation with the government of Huangpi District, the government departments have helped us to obtain the informed consent of the participants in advance, and the consent was verbal. The ethics committee of Wuhan University School of Medicine (WUSM) reviewed it, and verified it to comply with the Declaration of Helsinki and its revised version, as well as the relevant regulations of biomedical journals, and approved the research (No.2018YF0080).

\section{Consent for publication}

Not applicable.

\section{Availability of data and materials}

The data that support the findings of this study are available from the CDC of Huangpi district but restrictions apply to the availability of these data, which were used under license for the current study, and so are not publicly available. Data are however available from the authors upon reasonable request and with permission of the $\mathrm{CDC}$ of Huangpi district.

\section{Competing interests}

The authors declare that they have no competing interests.

\section{Funding}

Not applicable.

\section{Authors' contributions}

Xuyu Chen participated in the survey, the data analysis and the writing of the article. Hui Yao took part in the design of the study and the writing of the article. Li Ran and Wenwen Wu contributed to the data collection and screening. Yupeng Zhang and Mengying Li were involved in the data analysis and participated in the literature research. Xiaodong Tan and Ruihua Duan made a second revision to the manuscript. All authors have read and approved the final version.

\section{Acknowledgements}

We would like to thank Wuhan University and Huangpi District Center for Disease Control and Prevention for their support of this project, as well as the efforts of team partners in the project. 


\section{Author details}

1. School of Health Sciences, Wuhan University, Hubei, Donghu Road 115, Wuhcang District, 430000, China.

\section{References}

1. Starfield B, Macinko LSAJ. Contribution of Primary Care to Health Systems and Health. The Milbank Quarterly 2005.

2. Wang X, Yang H, Duan Z, Pan J. Spatial accessibility of primary health care in China: A case study in Sichuan Province. Soc Sci Med 2018;209:14-24.

3. Wu N, Lyu Z, Wang X. Stability of Health Workforce in Rural Health Service Institutions. Chinese General Practice 2015;18(10079572(2015)18:13<1498:XZWSJG>2.0.TX;2-613):1498-1503.

4. Yang L, Wang H, Xue L. What about the health workforce distribution in rural China? An assessment based on eight-year data. Rural Remote Health 2019;19(3):4978.

5. Wen T, Zhang Y, Wang X, Tang G. Factors influencing turnover intention among primary care doctors: a cross-sectional study in Chongqing, China. Hum Resour Health 2018;16(1):10.

6. Fang P, Liu X, Huang L, Zhang X, Fang Z. Factors that influence the turnover intention of Chinese village doctors based on the investigation results of Xiangyang City in Hubei Province. Int J Equity Health 2014;13:84.

7. Howard WH, Mcewan KA, Brinkman GL, Christensen JM. Human resource management on the farm: Attracting, keeping, and motivating labor. Agribusiness 2006;7(1):11-26.

8. Locke EA, Latham GP. Work motivation and satisfaction: Light at the end of the tunnel. Psychological Science 1990;1(4):240-246.

9. Xiongwen L. Management Dictionary. Shanghai: Shanghai Lexicographical Publishing House; 2013.

10. Emanuel F, Colombo L, Cortese CG, Ghislieri C. [The role of safety climate and the relationship with job satisfaction: an exploratory study across three different occupational contexts.]. G Ital Med Lav Ergon 2017;39(4):263-270.

11. Rains JJ. Job satisfaction among U.S. Department of the Army civilians: An analysis based on the Minnesota Satisfaction Questionnaire. 2011.

12. Smith PC, Kendall LM, Hulin CL. The Measurement of Satisfaction in Work and Retirement.

13. Shahnazi H, Daniali SS, Sharifirad G. Job satisfaction survey among health centers staff. International Journal of Health Promotion \& Education 2014;3:35.

14. Yukyeong CPD, Nan UPD, Richard PDPD. JOB SATISFACTION PERCEIVED BY MANAGERIAL PERSONNEL AND FOODSERVICE EMPLOYEES IN HOSPITAL FOODSERVICE DEPARTMENTS1. Foodservice Research International 2006;12(1):59-74.

15. Bowling NA, Hendricks EA, Wagner SH. Positive and Negative Affectivity and Facet Satisfaction: A Meta-analysis. Journal of Business \& Psychology 2008;23(3-4):115-125.

16. Sverke M, Hellgren J. The nature of job insecurity: Understanding employment uncertainty on the brink of a new millennium. APPLIED PSYCHOLOGY-AN INTERNATIONAL REVIEW-PSYCHOLOGIE APPLIQUEE-REVUE INTERNATIONALE 2002;51(1):23-42.

17. Y Z. The model study on the relationship between job satisfaction, career burnout and turnover intention among physicians from urban state-owned medical institutions: Fudan University; 2011.

18. Weiss DJ, Dawis RV, England GW. Manual for the Minnesota Satisfaction Question.

19. Spector PE. Job satisfaction: Application, assessment, causes, and consequences; 1997.

20. Smith PC, Kendall LM, Hulin CL. The measurement of satisfaction in work and retirement: A strategy for the study of attitudes. 1969;45(4):194.

21. Lu Y, Hu X, Huang X, Zhuang X, Guo P, Feng L, et al. Job satisfaction and associated factors among healthcare staff: a cross-sectional study in Guangdong Province, China. Bmj Open;6(7):e011388.

22. Li L, Hu H, Zhou H, He C, Fan L, Liu X, et al. Work stress, work motivation and their effects on job satisfaction in community health workers: a crosssectional survey in China. BMJ Open 2014;4(6):e004897-e004897.

23. Renjel RA, Ficalora R, Canaris G. Internal medicine physician job satisfaction in rural Montana and Northern Wyoming- a qualitative analysis. J Community Hosp Intern Med Perspect 2019;9(5):384-391.

24. Li H, Yuan B, Wang D, Meng Q. Motivating factors on performance of primary care workers in China: a systematic review and meta-analysis. BMJ Open 2019;9(11):e028619.

25. May SJRA. Spillover between Marital Quality and Job Satisfaction: Long-Term Patterns and Gender Differences. Journal of Marriage \& Family 2003;65(2):482-495.

26. Atefi N, Lim Abdullah K, Wong LP, Mazlom R. Factors influencing job satisfaction among registered nurses: a questionnaire survey in Mashhad, Iran. Journal of Nursing Management 2015;23(4):448-458.

27. Shahnazi H, Daniali SS, Sharifirad G. Job satisfaction survey among health centers staff. International Journal of Health Promotion \& Education 2014;3:35.

28. Faupel-Badger JM, E. ND, Grant I, P BJ. Career Satisfaction and Perceived Salary Competitiveness among Individuals Who Completed Postdoctoral Research Training in Cancer Prevention. Plos One 2017;12(1):e0169859-

29. Zhou H, Xueyan H, Juan Z, Jing S, Linlin H, Guangyu H, et al. Job Satisfaction and Associated Factors among Medical Staff in Tertiary Public Hospitals: Results from a National Cross-Sectional Survey in China. International Journal of Environmental Research \& Public Health 2018;15(7):1528- 
30. Azadeh A, Yazdanparast R, Zadeh SA, Keramati A. An intelligent algorithm for optimization of emergency department job and patient satisfaction. International Journal of Health Care Quality Assurance 2018;31(5).

31. Wisniewski JM, Jacinto C, Yeager VA, Castrucci B, Chapple-McGruder T, Gould E. Opportunities to Improve Employee Satisfaction Within State and Local Public Health Agencies. J Public Health Manag Pract 2019;25(5):440-447.

32. Han RM, Carter P, Champion JD. Relationships among factors affecting advanced practice registered nurses' job satisfaction and intent to leave. Journal of the American Association of Nurse Practitioners 2018;30(2):101-113.

33. Mattingly AN, Boyle CJ. Salary and entry-level requirements for pharmacy technicians compared with other health technologist and technician occupations in Maryland. J Am Pharm Assoc (2003) 2019.

34. Nomura Y, Okada A, Miyoshi J, Mukaida M, Akasaka E, Saigo K, et al. Willingness to Work and the Working Environment of Japanese Dental Hygienists. Int J Dent 2018;2018:2727193.

35. Klug K, Bernhard-Oettel C, Makikangas A, Kinnunen U, Sverke M. Development of perceived job insecurity among young workers: a latent class growth analysis. Int Arch Occup Environ Health 2019;92(6):901-918.

36. De Sio S, Cedrone F, Trovato BE, Buomprisco G, Perri R, Greco E. The Perception of Psychosocial Risks and Work-Related Stress in Relation to Job Insecurity and Gender Differences: A Cross-Sectional Study. Biomed Res Int 2018;2018:7649085.

37. Ford MT, Heinen BA, Langkamer KL. Work and family satisfaction and conflict: A meta-analysis of cross-domain relations. Journal of Applied Psychology;92(1):57-80.

38. Kunaviktikul W, Wichaikhum O, Nuntsupawat A, Nuntsupawat R, Chontawan R, Klunklin A, et al. Extended Work Hour and Patient, Nurse, and Organizational Outcomes in Thailand. International Journal of Evidence-Based Healthcare 2016.

39. Bailit JL, Weisberger A, Knotek J. Resident job satisfaction and quality of life before and after work hour reform. Journal of Reproductive Medicine 2005;50(9):649-652. 